\title{
Why and How Do Sojourners Talk about Macao? Effects of Perceived Risk and Expected Benefit
}

\author{
SUH-HEE CHOI $^{*} \cdot$ LISA TAM $^{* *} \cdot$ KADIR JUN AYHAN ${ }^{* * *} \cdot$ DONG-MIN LEE ${ }^{* * * *}$
}

Due to the growing popularity of digital platforms, social media conversations have been proposed and used as an indicator of public diplomacy outcomes. Despite this, existing research has found that most publics were unwilling to engage with foreign countries on social media. Considering this, this study seeks to identify factors that motivate and/or constrain individuals' engagement in conversations about foreign countries. A survey and semi-structured interviews were conducted with sojourners who temporarily resided in Macao. When choosing how (i.e., channels) and what (i.e., content) to transmit, they managed the tension between perceived risk and expected benefit. Reflecting the theory of planned behavior, where individuals' motivation (i.e., intended outcomes) and perceived behavioral control (i.e., ability to manage the tension between perceived risk and expected benefit to achieve such intended outcomes) predict behavioral intentions, the findings unveil the limitations of monitoring and tracking social media conversations as an indicator of public diplomacy outcomes.

Keywords: digital media, expected benefit, information selection, information transmission, Macao, perceived risk, sojourners

*Assistant Professor, Department of Geography, College of Sciences, Kyung Hee University, South Korea; Macao Institute for Tourism Studies ${ }^{* * * * *}$, China; E-mail: suhhee@khu.ac.kr

**Lecturer, School of Advertising, Marketing and Public Relations, QUT Business School, Australia; E-mail: 1.tam@qut.edu.au

***Corresponding author, Assistant Professor, Graduate School of International and Area Studies, Hankuk University of Foreign Studies, South Korea; E-mail: kadirayhan@gmail.com

****Assistant Professor, Department of Geography Education, Catholic Kwandong University, South Korea; E-mail: dr.dongminlee@gmail.com *****Suh-hee Choi was previously affiliated with Macao Institute for Tourism Studies, and this research was partly supported by Macao Institute for Tourism Studies.

DOI: 10.16934/isr.20.2.201912.29 


\section{INTRODUCTION}

Public diplomacy literature has been dominated by heuristic, normative and prescriptive studies. There have been numerous calls for the development of frameworks for evaluating public diplomacy effectiveness (Banks 2011; Hayden 2017; Pahlavi 2007; Pamment 2014; Sommerfeldt and Buhmann 2019). Recently, some studies have attempted to evaluate and assess public diplomacy outcomes and/or country images by listening to what foreign publics say about countries (Ingenhoff and Chariatte 2019; Ingenhoff, White, Buhmann and Kiousis 2019; Sevin and Ingenhoff 2018). These valuable contributions to the literature, however, do not take into account the factors that motivate and/or constrain foreign publics from engaging in conversations about countries, such as their motivations (i.e., intended outcomes) and their perceived behavioral control (i.e., their perceived ability to manage the tension between perceived risk and expected benefit to achieve the intended outcomes) (Ajzen 1991; Ajzen 2002). When not considered, these factors can create a major methodological problem, telling evaluators and assessors a different picture about the country of interest. Thus, this study aims to find out to what extent and how perceived risk and expected benefit play a role in individuals' communicative behaviors about foreign countries. Sojourners living in a foreign country were selected as a target group because, 1) they have direct experiences in that country, making their opinions more well-informed and more grounded on behavioral rather than symbolic communication (Tam and Kim 2019; Yun and Kim 2008); 2) they are likely to be conscious about expected benefit and perceived risk related to what they communicate about their country of residence. To that end, this paper analyzes how perceived risk and expected benefit affect their communicative behaviors (i.e., information selection and information transmission) in relation to their host country; and how and why sojourners transmit and do not transmit information about their host country. Macao was selected as the host region. This is further explained in the methodology section.

\section{LITERATURE REVIEW}

Public diplomacy is international or transnational actors' communicationbased activities to understand, inform and influence foreign publics, and build relationships with them to achieve foreign policy goals (Ayhan 2019; Cull 2013; Gregory 2008; Pamment 2018; Sevin 2017b). Generally identified as "government-to-people" contacts, public diplomacy is integral to foreign policy making such that its activities advocate for countries' foreign publics through cultivating favorable attitude towards those policies (Wang 2006). Based on a 
systematic review of public diplomacy literature, Sevin (2017a) argues that public diplomacy works three ways - public opinion, relationship dynamics, and public debates - which constitute the causal mechanisms between the communicationbased inputs and outcomes related to foreign policies. Public opinion, the first layer, focuses on country-led efforts to influence attitude and behaviors of foreign publics. From this perspective, countries pay attention to how they are perceived by foreign publics and invest money and efforts to foster a positive public opinion about themselves globally. Research about state-led public diplomacy on social media platforms has revealed their tendency of focusing on one-way communication. Dodd and Collins' (2017) analysis of embassies' Twitter accounts revealed, among Cull's (2008) five elements of public diplomacy-"listening," "advocacy," "cultural diplomacy," "exchange diplomacy," and "international news broadcasting"-Western embassies focused primarily on advocacy and Central-Eastern European embassies mainly focused on cultural diplomacy. A similar study in the Chinese context, which investigated Chinese social media accounts of foreign embassies, such as Weibo and WeChat, revealed challenges in actively engaging foreign publics and avoiding hostile and negative reactions from them (Jiang 2016).

This country-led approach overlooks the influence of individuals and non-state actors on international publics' attitudes and behaviors. Thus, the focus of public diplomacy has shifted from a one-dimensional approach to a relational, networked and collaborative approach (Yang and Taylor 2014; Zaharna, Arsenault and Fisher 2014), which is also illustrated by relationship dynamics and public debates (Sevin 2017a). Both state and non-state actors are critical for communicating and building relationships with foreign publics (Gilboa 2008; Melissen 2005). Communication about countries among global publics generate networked and amplified effects, affecting the international media environment and international public opinion (Vibber and Kim 2015). Through engaging in conversations about countries, individuals become important mediators who connect countries with the public around the globe (Payne 2009a). Individuals can positively and negatively influence the processes of public diplomacy (Cull 2008; Leong 2009; Yun and Vibber 2012). Inside-border foreign publics, such as temporary migrants or international students, who have first-hand direct experiences of living in foreign host countries are amongst the most influential in co-constructing images of the host country and creating mutual understanding between countries because they are physically and virtually connected with people in their home and host countries (Ayhan and Gouda 2019; Brinkerhoff 2019; Yun 2015; Yun and Toth 2009).

The networks among migrants, expatriates, students, and other sojourners are influential in yielding public diplomacy outcomes in home and host countries (Brinkerhoff 2019; Leong 2009; Levitt 2001). Sojourner and diaspora communities 
act as agents who maintain connections with people in their home countries; they advocate for or oppose to the issues in their home and the host countries (Brinkerhoff 2019; Leong 2009; Levitt 2001). In addition to the content of what they transmit about their home countries, what they say about their host countries is "a powerful opinion of the source country on the destination country" (Yun and Toth 2009, 500). Hence, public diplomacy practitioners must take into account not only foreign publics overseas, but also foreign publics sojourning or living in the country, prioritizing relationship building with them since they are important gatekeepers connecting people and institutions of their home and host countries (Yun and Toth 2009).

Thanks to the development of digital technologies, individuals at home and abroad have become significant providers of information about their home and host countries and are also mediators who facilitate transnational networks (Gilboa 2008; Leong 2009; Payne 2009b). Furthermore, considering their diverse levels of involvement in global information exchange, Fitzpatrick (2012) highlights that it is important for countries to identify and prioritize strategic publics, that is, those who participate in these interactions and have the ability to generate networks of influence among individuals and groups.

Individuals with international mobility are amongst the most active in transmitting information about their experiences about foreign countries (El Aouni, Cascón-pereira and Hernández-lara 2014; Yun 2014). For example, international exchange scholars and students are actively transmitting information about their unique life experiences in their host countries with people in their home countries (Yun 2012; Yun and Vibber 2012). Vibber's (2014) study revealed that international students' communicative behaviors about their host countries had affected the perceptions held by their families and friends in their home countries. A study on sojourners, non-permanent foreign residents who have no intention to reside in a foreign host country permanently, found that they are active in acquiring and transmitting information about the host country where they are living (Choi and Wu 2018). Because individuals' first-hand experiences of living in foreign countries are often unique and different from the stereotypical images presented in the mass media, the information they transmit is more influential in changing perceptions and attitudes (Grunig 1993; Grunig and Hung-Baesecke 2015). Therefore, public diplomacy practitioners are also advised to understand and respond to the opinion of these inside-border publics (Yun and Toth 2009).

In the digital age, countries have harnessed the capabilities of new technologies especially social media to engage with foreign publics (Cull 2013). Digital tools are employed to amplify traditional diplomatic efforts, inviting individuals to initiate and participate in conversations about foreign countries (Sotiriu 2015). Changes in beliefs and attitudes about host countries are often 
captured as indicators of public diplomacy outcomes (Sevin and Ingenhoff 2018). Despite its growing popularity, the use of digital media for diplomatic engagement has been criticized as a delusion (Comor and Bean 2012) and for promoting one-way advocacy (Dodd and Collins 2017). Moreover, most publics are unwilling to engage in discussing matters related to foreign countries on social media (Storie 2015).

Digital media is credited for contributing to public diplomacy by facilitating two-way interactive communication amongst global publics (Auer and Srugies 2013; Cull 2011; Khatib, Dutton and Thelwall 2012). With the proliferation of digital platforms on which publics can actively participate in discussing international affairs (Payne, Sevin and Bruya 2011), these publics form virtual communities beyond their physically fixed territories, creating a multiplier effect of local information (Seib 2011). In Haiti, communities of foreigners had higher levels of accessibilities to the Internet than the locals residing in their homeland (Navarrete and Huerta 2006) and were able to help promote US outreach efforts in the virtual space during the aftermath of the Haiti earthquakes (Seib 2011). Chinese people's sharing of thoughts and opinions about Europe on micro-blogs multiplied the effects of information spread (Song and Bian 2015).

Despite this bright side of amplification through digital media, there are conditions determining whether individuals choose to or not to transmit information. Singh (2015) posits that individuals' engagement in discussing international issues creates new meanings and leads to global transformation. However, Storie (2015) found that foreign publics were unwilling to discuss these issues online (i.e., lost publics). When confronting issues, they are more likely to engage with third parties such as local organizations (Storie 2018). Therefore, foreign publics' motivations or lack of motivations to engage in conversations about foreign countries should be further explored.

Acknowledging that numerous countries have invested in digitalized public diplomacy and have measured interactions on digital media as public diplomacy outcomes (Australian Government Department of Foreign Affairs and Trade 2016; Cull 2013; Ittefaq 2019; Sevin and Ingenhoff 2018; Sonenshine 2012), this study challenges the premise that the use of digital media amplifies the effects of public diplomacy. Although it is assumed that the interactions facilitated through digital platforms construct new meanings that positively affect global outcomes (Singh 2015), the conditions under which individuals are willing or unwilling to engage in these interactions should be further explored. Situating this study in the context of sojourners in Macao, this study proposes to address the research questions: 
RQ1: How do perceived risk and expected benefit affect their communicative behaviors (i.e., information selection and information transmission) in relation to Macao?

RQ2: How and why do sojourners transmit and do not transmit information about Macao?

\section{THEORETICAL FRAMEWORK}

This study considers perceived risk and expected benefit as main variables which affect foreign publics' motivation to engage in communicative behaviors by applying the Communicative Action in Problem Solving (CAPS) framework. The CAPS framework consists of three communicative behaviors that describe individuals' communicative activeness: information acquisition, information selection, and information transmission (Ni and Kim 2009). This framework originates from the Situational Theory of Problem Solving which posits that when individuals face and recognize a problem (i.e., high problem recognition), will feel personally connected to the problem (i.e., high involvement recognition) and feel capable of solving the problem (i.e., low constraint recognition), they will be actively seeking, selecting and transmitting information about the problem (Kim and Grunig 2011). Individuals can either be specific and strategic in processing information relevant to the problem (i.e., proactive) or accepting any information that assists them in solving the problem (i.e., passive). Subsequently, they can be either be passive in transmitting information (i.e., sharing information only when someone asks for the information) or proactive in information forwarding (i.e., finding opportunities to deliver information related to the problem).

Applying the CAPS framework to the present study, this study seeks to understand perceived risk and expected benefit as antecedents affecting sojourners' activeness in selecting and transmitting information about a host country. Perceived risk is defined as negative outcomes which may occur as a result of a behavior whereas expected benefit refers to beliefs about the positive outcomes resulting from the behavior (Liu, Brock, Shi, Chu and Tseng 2013). When deciding whether to engage in a behavior, individuals have to negotiate and manage the tension between perceived risk and expected benefit. For example, social media use helps individuals maintain interpersonal relationships (i.e., expected benefit) but it also exposes them to privacy invasion (i.e., perceived risk) (Debatin, Lovejoy, Horn and Hughes 2009). In the tourism context, expected benefit such as altruistic and community-related motivations has been identified as factors motivating information transmitting on social media (Munar and Jacobsen 2014). 


\section{METHODOLOGY}

\section{Context of this study}

To explore the effects of perceived risk and expected benefit on how and why sojourners share information about a host country, this study adopts a mixed-methods research design. A survey was conducted to explore how sojourners in Macao manage the tension between perceived risk and expected benefit when deciding whether they should be proactive or passive in information selection and information transmission when sharing information about Macao. Furthermore, interviews were conducted to have a more in-depth understanding of individuals' interpretations of perceived risk and expected benefit, complementing the survey findings. While the survey items were adopted from the existing CAPS framework ( $\mathrm{Ni}$ and Kim 2009), the interview data also sought to investigate individuals' explanations of the causes of their communicative behaviors.

To enhance validity and generalizability of the findings, the interaction between the research question to be addressed and the context must be examined (Yin 2013). Because this study seeks to uncover how and why individuals transmit and do not transmit information (which is a premise that affects the amplification of public diplomacy), this study selected sojourners in Macao, Special Administrative Region (SAR) of China, as a context. Macao was selected because of its regional scope, uniqueness, and the potential to provide implications to academia and other regions. First, because the regional scope is small enough, with a size of about 30 square kilometers, sojourners are expected to experience the social system and the physical living environment relatively similar.

Second, Macao has its merit because it is home to many sojourners from different countries and regions who temporarily reside in the region especially for work. As of the end of the second quarter in 2019, among a total population of 672,000, there were 190,367 non-resident workers in Macao (Government of Macao Special Administrative Region Statistics and Census Service 2019a). Non-resident workers accounted for 28 per cent of Macao's population. As individuals with first-hand experiences of living in Macao, it is expected that they are active in transmitting information about their day-to-day experiences of living in Macao and that the information that they transmit is unique and different from stereotypical images presented in the mass media (Choi and $\mathrm{Wu}$ 2018; Grunig 1993). Furthermore, Macao's GDP has been highly dependent on tourism, gaming, finance, insurance, and other service sector industries (Sheng and $\mathrm{Gu}$ 2018). In 2018, 35,803,663 people visited Macao. During the same period of time, Macao’s GDP was 440.3 billion Macao Patacas ( 54.46 billion US Dollars) 
and its gaming revenue was 302.8 billion Macao Patacas (37.57 billion US Dollars), making the gaming industry's share in Macao's GDP nearly 70\% (Gaming Inspection and Coordination Bureau of Macao SAR 2019; Government of Macao Special Administrative Region Statistics and Census Service 2019b). Macao's dependence on service sectors, particularly tourism and gaming, and a high ratio of sojourners in the population makes relationship dynamics and public debates about Macao very important for this host region (Sevin 2017a). Therefore, Macao was selected to explore sojourners' communicate behaviors related to this polity.

Last, the findings reflect the region-specific communicative behaviors of sojourners, which have potentials to provide implications for theory and practice of public diplomacy. The study area is in a unique position as a Special Administrative Region of China. Sojourners are expected to be conscious about the political actions and the perceived control of the Chinese as well as the regional government which are different from their home countries and are likely to be quite authoritative (Lei 2019). Simultaneously, both external and internal motivations for communicative behaviors are expected among the study subjects in this region. Residing in the Las Vegas of the East, which also has a UNESCO Heritage Site and neighbors a well-known international city of Hong Kong and mainland China, causes them to be motivated-and triggered-to talk about the issues about the region. Furthermore, their status as sojourners causes them to be exposed to an environment, new and unfamiliar to them, which would lead them to be under circumstances to solve issues they encounter through communication with others, as the Situational Theory of Problem Solving (Kim and Grunig 2011) suggests.

Furthermore, in contrary to Hong Kong, where the Umbrella Movement and the ongoing Hong Kong protests have triggered academic interest in the media exposure pattern and their diplomatic implications as well as the communicative behaviors and the external and internal censorship of professional journalists and lay informatics (Darbo and Skjerdal 2019), there has been surprisingly a lack of regional interest in Macao, the neighboring region with the equivalent political status as Hong Kong. This study fills in the research gaps by focusing on this under-researched region. The interpretations of expected benefit and perceived risk could differ from country to country or region to region. But the general conceptual framework (i.e., the effects of perceived risk and expected benefit on predicting communicative behaviors) could be generally applied to other areas. 


\section{Surveys}

Using a mall intercept technique (Butler 2008), sojourners living in Macao were approached in popular public areas who were asked by trained surveyors to complete a questionnaire either in English or Chinese. The questionnaire had one statement measuring perceived risk [PR], five statements measuring expected benefit [EB], four statements measuring information selection [IS] and information transmission [IT], and demographic questions. The statements were measured on a continuous scale with 0 representing "do not agree at all" and 100 "totally agree."

A series of simple linear regressions were conducted on SPSS, with a significance level of .05. Perceived risk and expected benefit were independent variables. Two statements about proactive and passive information selection, respectively, and two other statements about proactive and passive information transmission were dependent variables. After removing the invalid responses, a total of 320 responses were used for the analysis. Among the respondents, $50 \%$ $(n=160)$ were male and 50\% $(n=160)$ were female. $12.2 \%(n=39)$ were below 24 years old; $26.6 \%(n=117)$ were between 25 and 34 years of age; 30.3\% $(n=97)$ were between 35 and 44; 17.2\% $(n=55)$ were between 45 and 54; 3.4\% $(n=11)$ were between 55 and 64 years old; and .3\% $(\mathrm{n}=1)$ was above 65 years old; $48.1 \%$ $(n=154)$ were married and 47.2\% $(n=151)$ single; and $4.7 \%(n=15)$ were others. More than $60 \%$ of the respondents had lived in Macao for one to five years, and among the remaining respondents, about 30\% had lived in Macao for more than five to ten years.

Table 1 indicates the descriptive statistics on survey respondents' activeness in online communication. The mean values of all the three items for the activeness are over 70 and skewed to the left. They were very active in Internet usage (mean=77.51). The mean value for the statement "I am a heavy user of social media" was relatively lower (mean=72.26) and it had a higher standard deviation (Std. Deviation=23.107). They also expressed that they were heavy users of messaging applications (mean=75.27).

\section{TABLE 1. DESCRIPTIVE STATISICS ON RESPONDENTS' ACTIVENESS IN ONLINE} COMMUNICATION

\begin{tabular}{lcccc}
\hline & Mean & Std. Deviation & Skewness & Kurtosis \\
\hline I am a heavy user of the Internet. & 77.51 & 19.008 & -1.242 & 2.211 \\
\hline I am a heavy user of social media. & 72.26 & 23.107 & -1.295 & 1.644 \\
\hline I am a heavy user of mobile messengers. & 75.27 & 21.492 & -1.251 & 1.750 \\
\hline
\end{tabular}

Source: The authors' computation 
Figure 1 shows the statements used to measure perceived risk [PR], expected benefit [EB], information selection [IS], and information transmission [IT]. Corresponding to the findings of the interviews, the statements measured (a) perceived risk as the feeling of insecurity in Macao (measured using one statement), (b) expected benefit as the perceptions of benefit to information recipients (measured using five statements), (c) information selection as selectively ignoring information deemed unreliable (i.e., proactive) and/or welcoming any information (i.e., passive) (with one statement each), and (d) information transmission as proactively giving information about Macao (i.e., proactive) and/or sharing only if someone else asks (i.e., passive) (with one statement each).

Independent Variables

Perceived Risk $[\mathrm{PR}]$
PR1: I feel insecure living in
Macao.

\section{Expected Benefit [EB]}

EB1: People around me learn unique things about Macao.

EB2: People around me intend to visit Macao.

EB3: People around me become more familiar with Macao.

EB4: People around me have special feelings about Macao. EB5: People around me like Macao more than before.

\section{Dependent Variables}

Information Selection [IS]

IS1: I ignore information that I

do not think is reliable about

Macao. (proactive)

IS2: I welcome any information

about Macao. (passive)

Information Transmission [IT]

IT1: I look for chances to give

information about Macao.

(proactive)

IT2: I am willing to talk about Macao if something else asks. (passive)

\section{FIGURE 1. STAEMENTS USED TO MEASURE PERCEIVED RISKS [PR], EXPECTED BENEFITS [EB], INFORMATION SELECTION [IS], AND INFORMATION TRANSMISSION [IT].}

\section{Interviews}

Simultaneously, sojourners were interviewed individually between July 2015 and June 2016. Purposive sampling was used, and the informants were approached to include sojourners from different age groups, nationalities, and occupations. Recruiting messages were posted on the Facebook groups that sojourners in Macao frequently used. The interviews were semi-structured and were conducted in reasonably quiet spaces, such as in a classroom on a college campus. The interviews lasted an average of one hour. The interviews were audio-recorded and transcribed. The data were coded using bottom-up thematic 
analysis (Braun and Clarke 2006). First, repeated expressions in the raw data were synthesized to identify meaningful themes related to the respondents' experiences in, perceptions about, and attitudes toward their communicative behaviors about Macao. Second, the themes were reorganized based on the relations and hierarchy among them. Third, meaningful patterns among the themes were drawn.

This is a part of a bigger project which involved a total of 27 interviews including foreigners, Chinese from other regions, foreign workers and their family members as well as international students. A combination of interviews and the survey provided insights into understanding the sojourners' communication patterns. Among the 27 interviewees, eight sojourners' statements are focused on and being reported, considering the depths and the scope of the communication experiences they reported, and thus the profile of them are provided in Table 2. All the eight interviewees had lived in Macao for at least one month and were still residing in Macao during the time of the interview. On average, they have lived in Macao for two and a half years. Out of the eight participants, six were female and two were male. Their ages ranged from late twenties to early sixties. As of countries of origin, three of them came from Asian countries (Philippines, Malaysia, and South Korea), four from the United States and Canada, and one from the United Kingdom. Six of them were professionals and two of them were housewives.

\section{TABLE 2. DEMOGRAPHIC INFORMATION ABOUT RESPONDENTS}

\begin{tabular}{cccccc}
\hline ID & Gender & Age Group & Occupation & Country of Origin & Duration of Residence in Macao \\
\hline$\# 1$ & Female & $51-55$ & Professional & USA & 2 years \\
\hline$\# 2$ & Female & $61-65$ & Housewife & USA & 3 months \\
\hline$\# 3$ & Male & $31-35$ & Professional & Malaysia & 1 month \\
\hline$\# 4$ & Female & $51-55$ & Professional & USA & 8 years \\
\hline$\# 5$ & Male & $31-35$ & Professional & Canada & 3 years \\
\hline$\# 6$ & Female & $36-40$ & Professional & Philippines & 11 months \\
\hline$\# 7$ & Female & $46-50$ & Housewife & United Kingdom & 11 months \\
\hline$\# 8$ & Female & $26-30$ & Professional & South Korea & 3 years \\
\hline
\end{tabular}

\section{FINDINGS}

\section{Testing associations between perceived risk and expected benefit and communicative} behaviors (from survey data)

The survey data was used to test possible associations between perceived risk [PR] and expected benefit [EB] as independent variables and communicative 
behaviors (i.e., information selection [IS] and information transmission [IT]) as dependent variables. Results from linear regression yielded statistical values displayed in Table 2 (with $\mathrm{F}$ indicating the overall significance of the regression model, $\mathrm{p}>.05$ as not statistically significant, and R2 indicating the percentage of variance for the dependent variable explained by each independent variable). The higher the $\mathrm{R}^{2}$, the more the variance in the dependent variable that the independent variable explains. Although most of these regression models are significant, it must be noted that a small $\mathrm{R}^{2}$ is considered to have limited explanatory power.

\section{TABLE 3. RESULTS FROM LINEAR REGRESSION MODELS}

\begin{tabular}{|c|c|c|c|c|}
\hline \multirow[b]{2}{*}{ Independent variables } & \multicolumn{4}{|c|}{ Dependent variables } \\
\hline & $\begin{array}{l}\text { IS1: I ignore } \\
\text { information that I } \\
\text { do not think is } \\
\text { reliable about } \\
\text { Macao. (proactive) }\end{array}$ & $\begin{array}{l}\text { IS2: I welcome } \\
\text { any information } \\
\text { about Macao. } \\
\text { (passive) }\end{array}$ & $\begin{array}{l}\text { IT1: I look for } \\
\text { chances to give } \\
\text { information about } \\
\text { Macao. (proactive) }\end{array}$ & $\begin{array}{l}\text { IT2: I am willing } \\
\text { to talk about } \\
\text { Macao if } \\
\text { something else } \\
\text { asks. (passive) }\end{array}$ \\
\hline $\begin{array}{l}\text { PR1: I feel insecure } \\
\text { living in Macao. }\end{array}$ & $\begin{array}{c}\mathrm{F}=.028 \\
\mathrm{R}^{2}<.001\end{array}$ & $\begin{array}{c}\mathrm{F}=.309 \\
\mathrm{R}^{2}=.001\end{array}$ & $\begin{array}{l}\mathrm{F}=4.526^{*} \\
\mathrm{R}^{2}=.014\end{array}$ & $\begin{array}{l}\mathrm{F}=3.320 \\
\mathrm{R}^{2}=.010\end{array}$ \\
\hline $\begin{array}{l}\text { EB1: People around me } \\
\text { learn unique } \\
\text { things about } \\
\text { Macao. }\end{array}$ & $\begin{array}{l}\mathrm{F}=30.175^{* * *} \\
\mathrm{R}^{2}=.087\end{array}$ & $\begin{array}{c}\mathrm{F}=36.103^{* * *} \\
\mathrm{R}^{2}=.102\end{array}$ & $\begin{array}{c}\mathrm{F}=54.903^{* * *} \\
\mathrm{R}^{2}=.147\end{array}$ & $\begin{array}{c}\mathrm{F}=38.696^{* * *} \\
\mathrm{R}^{2}=.108\end{array}$ \\
\hline $\begin{array}{l}\text { EB2: People around me } \\
\text { intend to visit } \\
\text { Macao. }\end{array}$ & $\begin{array}{c}\mathrm{F}=18.305^{* * *} \\
\mathrm{R}^{2}=.054\end{array}$ & $\begin{array}{l}\mathrm{F}=6.369^{*} \\
\mathrm{R}^{2}=.020\end{array}$ & $\begin{array}{c}\mathrm{F}=20.154^{* * *} \\
\mathrm{R}^{2}=.060\end{array}$ & $\begin{array}{c}\mathrm{F}=32.476^{* * *} \\
\mathrm{R}^{2}=.093\end{array}$ \\
\hline $\begin{array}{l}\text { EB3: People around me } \\
\text { become more } \\
\text { familiar with } \\
\text { Macao. }\end{array}$ & $\begin{array}{l}\mathrm{F}=19.096^{* * *} \\
\mathrm{R}^{2}=.057\end{array}$ & $\begin{array}{c}\mathrm{F}=49.714^{* * *} \\
\mathrm{R}^{2}=.135\end{array}$ & $\begin{array}{l}\mathrm{F}=36.839^{* * *} \\
\mathrm{R}^{2}=.104\end{array}$ & $\begin{array}{c}\mathrm{F}=14.392^{* * *} \\
\mathrm{R}^{2}=.043\end{array}$ \\
\hline $\begin{array}{l}\text { EB4: People around me } \\
\text { have special } \\
\text { feelings about } \\
\text { Macao. }\end{array}$ & $\begin{array}{c}\mathrm{F}=42.108^{* * *} \\
\mathrm{R}^{2}=.117\end{array}$ & $\begin{array}{c}\mathrm{F}=54.717^{* * *} \\
\mathrm{R}^{2}=.147\end{array}$ & $\begin{array}{l}\mathrm{F}=94.562^{* * *} \\
\mathrm{R}^{2}=.229\end{array}$ & $\begin{array}{c}\mathrm{F}=19.344^{* * *} \\
\mathrm{R}^{2}=.057\end{array}$ \\
\hline $\begin{array}{l}\text { EB5: People around me } \\
\text { like Macao more } \\
\text { than before. }\end{array}$ & $\begin{array}{c}\mathrm{F}=26.053^{* * *} \\
\mathrm{R}^{2}=.076\end{array}$ & $\begin{array}{c}\mathrm{F}=23.603^{* * *} \\
\mathrm{R}^{2}=.069\end{array}$ & $\begin{array}{c}\mathrm{F}=71.258^{* * *} \\
\mathrm{R}^{2}=.183\end{array}$ & $\begin{array}{c}\mathrm{F}=22.306^{* * *} \\
\mathrm{R}^{2}=.066\end{array}$ \\
\hline
\end{tabular}

Source: Regression results

Note: $\mathrm{PR}=$ perceived risk. $\mathrm{EB}=$ expected benefit. $\mathrm{IS}=$ information selection. $\mathrm{IT}=$ information transmission. ${ }^{*} p<.05,{ }^{* *} p<.01,{ }^{* * *} p<.001$.

First, for models with perceived risk [PR1] as an independent variable, the $\mathrm{p}$-values showed that the linear models were not statistically meaningful. Out of the four linear models generated, the highest $\mathrm{R}^{2}$ was .014 (for proactive information transmission). It indicated that only $1.4 \%$ of the variance is explained by perceived risk. This finding shows that perceived risk cannot explain whether individuals are proactive or passive in selecting and transmitting information about Macao. 
Second, for the first statement of expected benefit [EB1] which measures the expected positive outcome of helping others learn unique things about Macao, $\mathrm{R}^{2}$ was higher in all the four linear models. For proactive information selection [IS1], the statement explains $8.7 \%$ of the variance. For passive information selection [IS2], the statement explains $10.2 \%$ of the variance. For proactive information transmission [IT1], the statement explains $14.7 \%$ of the variance. For passive information transmission [IT2], it explains $10.8 \%$ of the variance. Therefore, the expected benefit of transmitting unique information about Macao is meaningful in explaining variations in information selection and transmission.

Third, for the second statement of expected benefit [EB2] which measures the expected outcome of increasing intention to visit Macao, $\mathrm{R}^{2}$ was relatively lower. For proactive information selection [IS1], the statement explains $5.4 \%$ of the variance. For passive information selection [IS2], the statement explains $2.0 \%$ of the variance. For proactive information transmission [IT1], the statement explains $6.0 \%$ of the variance. For passive information transmission [IT2], the statement explains $9.3 \%$ of the variance. Compared to EB1, this statement is not as meaningful in explaining variations in information selection and transmission.

Fourth, for the third statement of expected benefit [EB3] which measures the expected outcome of increasing familiarity about Macao, $\mathrm{R}^{2}$ was higher for passive information selection [IS2] and proactive information transmission [IT1]. It explains $5.7 \%$ of the variance for proactive information selection [IS1] and 4.3 $\%$ for passive information transmission [IT2]. However, it explains $13.5 \%$ for passive information selection [IS2] and $10.4 \%$ for proactive information transmission [IT1]. This finding indicates that sojourners who wish to help increase others' familiarity about Macao welcome new information about Macao and are active in finding opportunities to transmit this information.

Fifth, for the fourth statement of expected benefit [EB4] which measures the expected outcome of enhancing special feelings about Macao, $\mathrm{R}^{2}$ shows that the statement is meaningful in explaining proactive information selection [IS1] at $11.7 \%$, passive information selection [IS2] at $14.7 \%$ and proactive information transmission [IT1] at $22.9 \%$. However, it is not as meaningful in explaining passive information transmission [IT2] (at 5.7\%).

Lastly, for the fifth statement of expected benefit [EB5] which measures the expected outcome of increasing favorability about Macao, $\mathrm{R}^{2}$ shows that it is meaningful in explaining proactive information transmission [IT1] at $18.3 \%$. It is not as meaningful in explaining proactive information selection [IS1] (at 7.6\%), passive information selection [IS2] (at 6.9\%) and passive information transmission [IT2] (at 6.6\%). 


\section{Interpretations of perceived risk and expected benefit (from interview data)}

The interview data showed that the respondents expressed different types of perceived risk associated with information transmission. First, participants had expressed concerns about the threat of job stability. Respondent \#5 pointed out that he did not post any negative experiences about his workplace: "I don't post things about hardships in my workplace because colleagues from my company could read my posts on Facebook." He also avoided posting positive information because he was afraid that it would result in negative reactions from information recipients at home: "I was careful when I posted pictures of upscale restaurants and luxury hotels." Second, respondents had expressed perceived risk related to their immigration status. Careless information transmission could impede their career, quality of life, or even their status as temporary residents. Although they voluntarily moved to Macao for work, they hesitated to talk about the difficulties they faced as sojourners in Macao. Respondent \#4 shared the fear of losing her immigration status: "I think, as a foreigner, you always have to be careful about what you might state openly politically because they might just refuse to renew your white card [Macao's non-permanent resident ID]." She added that "There are things that can happen in Macao, and people don't voice anything because they want to stay here. They don't make a comment because they want to keep their jobs and their status."

To cope with perceived risk, respondents carefully selected the platforms on which they transmitted information about Macao. They avoided using platforms which could expose information to an unknown public. When transmitting information publicly, they chose not to reveal their identities or only to discuss topics which were not sensitive such as topics not related to Macao.

Respondent \#3 evaluated the different levels of privacy protection of different platforms:

"I use it [i.e., Facebook], but not so actively. Not like every hour, every day. Once or twice a week, [I] login and see what's up. I don't post pictures and stuff because I enjoy privacy because there are too many people on Facebook. You have your work colleagues, you have your family, you have your little niece and kids. You don't want locals to know what you are doing and where you are. So, I like to keep things private and confidential."

He preferred Instagram to Facebook as an outcome of different levels of perceived risk across the two different platforms: 
"I uploaded some pictures on Instagram because you know who your followers are $\cdots$ But, for Facebook, there's a privacy issue. Sometimes you want to keep some pictures [confidential]. You don't want everyone to see it."

The same concern was expressed by other respondents. Respondent \#4 reported that she preferred to use social media privately when she posted her experiences of living in Macao on Facebook: "My Facebook page is private, friends only, and if somebody wants to tag a photo, I have to give permission." She added, "I put mostly pictures so the family can see." Similarly, Respondent \#5 posted information on Facebook in a restrictive manner. Rather than restricting the audience, he was selective about the content he posts to make sure it would meet the audience's expectations. He illustrated his selectivity by stating that, "I am conscious of the audience when I post. I select the content of the posting that the audience would enjoy watching." He added:

"Whenever I use social media, I am conscious of the fact that what I post will be shared with others. I post what I myself was surprised with, and the things that may be of interest to others. I am conscious of others because I post things to show others. It can be taken as the consideration of others, and it can also be seen as showing good things only."

Respondent \#6 deactivated her Facebook account after moving to Macao because she wished to separate her professional life from her personal life. She stated, "I just want to connect with others through Viber and Gmail without having to expose myself fully." Therefore, she selected closed platforms to transmit information about Macao. She added, "I do like taking pictures, but I share them in my own networks. I email friends."

Despite the perceived risk, the respondents also discussed the expected benefit of transmitting information. They explained that they would transmit on platforms with lower perceived threat and higher perceived control. Respondent \#7 used Facebook relatively active, but she selected this platform because of her audience, especially her family. She elaborated on the benefit of posting to stay in touch with her family: "I like Facebook, and I use social media and phone to keep in touch with my family. We use WhatsApp, Viber, and FaceTime to keep in touch." There was also a focus on the uniqueness of information transmitted:

"When we first arrived in Macao, my husband used to take pictures of the old part of Macao and the old part of Taipa. I used to take pictures when I went hiking in Coloane at the beach and up in the hills." 
Instead of using Facebook, Respondent \#8 used her blog and messaging apps for personal conversations. She had a blog about Macao and her motivation for posting information through her blog was "to find potential opportunities." She stated, "I slightly expect that blogging would be practically beneficial. So, I continue blogging." Her reaction is consistent with the benefit-driven motivation for the layperson to participate in information transmitting (Rehmet and Dinnie 2013). Respondent \#1 used Facebook to post news about local events. She said, "If I post something, it's an invitation for people to join me to do something in Macao." While she defined the invitation to attend functions in the category of "not personal things," she used emails to transmit information about her personal life in Macao. She stated, "If I write something, it's in an email that I send to people I know intimately. There's no stranger involved. The decision of not posting something publicly is extremely personal." Respondent \#2 echoed the utilization of emails as a controlled means of communication:

"I wrote our Christmas letter, and, at the end of the letter, I attached a link, because we only send it by email - I attached a link of a $\cdots$ tour of Macao by air, and the narration showing the cultural differences from air looking down between the Portuguese and [Chinese] $\cdots$ I attached it to our letter when I sent [it] out to about four hundred something people. 'These are the cultural spots. We hope you are coming to see us, learning about another part of the country.'"

\section{DISCUSSION AND CONCLUSION}

This study was conducted in acknowledgement of government agencies' deliberate attempts to strengthen or change knowledge, attitudes, and behaviors about their countries. Nevertheless, the communicative behaviors of individuals are beyond their control because communicative behaviors are co-constructed with diverse stakeholders through complex interactions in a marketplace of images (Ayhan 2018; Buhmann and Ingenhoff 2015). The findings from this study have attested the importance of the communicative behaviors of sojourners as one of the most influential stakeholders in public diplomacy. First, expected benefit enhances their information selection and transmission. The interview data further showed that the information that they transmit is mostly related to their unique life experiences in Macao that they believe their audience will benefit from. This is consistent with the view that inside-border foreign publics, who have experiential relationships with their host countries, have their relationships founded upon uniquely personal experiences, which are different from the stereotypical images portrayed by the media (Grunig 1993; Grunig and 
Hung-Baesecke 2015), making them critical transmitters of information between counterparts in their home and host countries. Second, although perceived risk does not explain variations in activeness in information selection and information transmission, it causes these sojourners to choose the content and the platforms on which they transmit selectively. While the single-item variable to measure perceived risk in the survey was not able to capture the perceived behavioral control of sojourners, in-depth interviews revealed the reasons for sojourners' self-censorship in their communicative actions on digital platforms such as the perceived risk of losing their work rights.

This study fills in the research gaps and responds to calls for more empirical studies to address the assumptions for public diplomacy evaluations (Pamment 2013). Against the backdrop of government agencies' deliberate attempts to strengthen or change knowledge, attitudes and behaviors about their countries, this study argues that the communicative behaviors of individuals and non-state actors are beyond their control as these behaviors are co-constructed with diverse stakeholders through complex interactions in a marketplace of images (Ayhan 2018; Buhmann and Ingenhoff 2015). In understanding foreign publics' patterns of communication, this study was developed based on the theories that explain motivation and perceived behavioral control including the Theory of Planned Behavior (Ajzen 1991; Ajzen 2002) and the Situational Theory of Problem Solving (Kim and Grunig 2011).

This study has contributed to the body of knowledge in public diplomacy and country image by applying the CAPS framework to explore the antecedents of sojourners' communicative behaviors about a host region. The findings challenge existing research which suggests monitoring and measuring social media conversations as public diplomacy outcomes (Sevin and Ingenhoff 2018). Listening to foreign publics (Cull 2010) and using them as a resource to promote a country (Seib 2011) are amongst the most frequently discussed themes within public diplomacy. However, this study found that sojourners in Macao are motivated to transmit only selected information on selected platforms. They self-censored themselves in order to negotiate and manage the tension between perceived risk and expected benefit. Countries are increasingly advised to harness the potential of digital media to engage and to measure how social media conversations amplify the effects of such engagement (Spry 2018) but this is a problematic premise. Countries must not only consider what has been transmitted and can be measured, but also what has not been transmitted and why it has not been so. There were experiences that were not being transmitted on open platforms such as social media but were transmitted on closed platforms, such as emails and personal messages. Closed platforms facilitate interpersonal exchanges which are more intimate and persuasive. These findings encourage more research into autonomous networked communication between individuals, whose private 
conversations may generate significant political consequences for countries, particularly when they mobilize certain actions through these communicative behaviors (Castells 2009). Hence, the findings reveal that there are limitations in monitoring and tracking social media conversations as an indicator of public diplomacy outcomes. Especially, monitoring and tracking communicative behaviors of foreign publics on social media related to relatively authoritarian countries would potentially tell a very different picture than more genuine conversations taking place on more private "mass self-communication" (Castells 2009) mediums. However, studying what is communicated in these private conversations would not be possible since they are not readily available as in the case of social media conversations. When deciding how to evaluate public diplomacy outcomes, researchers and practitioners must consider how individuals manage the tension between perceived risk and expected benefit before deciding what and on which channels they communicate in relation to their country of interest. As public diplomacy and international relations are intertwined such that public diplomacy is an instrumental tool to achieve favorable international public opinion about a country's foreign policy, governments should consider the significance of sojourners in facilitating the process.

\section{REFERENCES}

Ajzen, Icek. 2002. "Perceived Behavioral Control, Self-Efficacy, Locus of Control, and the Theory of Planned Behavior 1." Journal of Applied Social Psychology 32(4): 665-683.

Ajzen, Icek. 1991. "The Theory of Planned Behavior." Organizational Behavior and Human Decision Processes 50(2): 179-211.

Auer, Claudia and Alice Srugies. 2013. Public Diplomacy in Germany. Cpd Perspectives on Public Diplomacy Paper 5. Los Angeles, CA: Figueroa Press.

Australian Government Department of Foreign Affairs and Trade. 2016. "Digital Media Strategy 2016-18."

Ayhan, Kadir Jun. 2019. "The Boundaries of Public Diplomacy and Non-State Actors: A Taxonomy of Perspectives." International Studies Perspectives 20(1): 63-83.

Ayhan, Kadir Jun. 2018. "Branding Korea as "My Friend's Country": The Case of Vank's Cyber Public Diplomats." Korea Observer 49(1): 51-81.

Ayhan, Kadir Jun and Moamen Gouda. "Talking About Korea: Analyzing the Determinants of Korean Government Scholarship Recipients' Word-ofMouth About Korea." Paper presented at the ISA Asia-Pacific Conference 2019, Singapore. 
Banks, Robert. 2011. "A Resource Guide to Public Diplomacy Evaluation (Cpd Perspectives on Public Diplomacy)." Los Angeles, CA: USC Center on Public Diplomacy at the Annenberg School University of Southern California.

Braun, Virginia and Victoria Clarke. 2006. "Using Thematic Analysis in Psychology." Qualitative Research in Psychology 3(2): 77-101.

Brinkerhoff, Jennifer M. 2019. "Diasporas and Public Diplomacy: Distinctions and Future Prospects." Hague Journal of Diplomacy 14(1-2): 51-64.

Buhmann, A. and D. Ingenhoff. 2015. "Advancing the Country Image Construct from a Public Relations Perspective: From Model to Measurement." Journal of Communication Management 19(1): 62-80.

Butler, S. 2008. "Mall Intercept Survey." In Encyclopedia of Survey Research Methods edited by D. P. J. J. Lavrakas, 448-449. Thousand Oaks: Sage. Castells, Manuel. 2009. Communication Power. Oxford: Oxford University Press. Choi, Suh-hee and Hung-Che Wu. 2018. "Tourism Communicative Actions of Sojourners and Information Recipients." Journal of Destination Marketing \& Management 9: 279-287.

Comor, E. and H. Bean. 2012. "America's "Engagement" Delusion: Critiquing a Public Diplomacy Consensus." International Communication Gazette 74(3): 203-220.

Cull, Nicholas J. 2013. "The Long Road to Public Diplomacy 2.0: The Internet in Us Public Diplomacy." International Studies Review 15(1): 123-139.

Cull, Nicholas J. 2010. "Public Diplomacy: Seven Lessons for Its Future from Its Past." Place Branding and Public Diplomacy 6(1): 11-17.

Cull, Nicholas J. 2008. "Public Diplomacy: Taxonomies and Histories." Annals of the American Academy of Political and Social Science 616(1): 31-54.

Cull, Nicholas J. 2011. "Wikileaks, Public Diplomacy 2.0 and the State of Digital Public Diplomacy." Place Branding and Public Diplomacy 7(1): 1-8.

Darbo, Karoline Nerdalen and Terje Skjerdal. 2019. "Blurred Boundaries: Citizens Journalists Versus Conventional Journalists in Hong Kong." Global Media and China 4(1): 111-124.

Debatin, B., J. P. Lovejoy, A. K. Horn, and B. N. Hughes. 2009. "Facebook and Online Privacy: Attitudes, Behaviors, and Unintended Consequences." Journal of Computer-Mediated Communication 15(1): 83-108.

Dodd, Melissa D. and Steve J. Collins. 2017. "Public Relations Message Strategies and Public Diplomacy 2.0: An Empirical Analysis Using Central-Eastern European and Western Embassy Twitter Accounts." Public Relations Review 43(2): 417-425.

El Aouni, Fatimazohra, Rosalía Cascón-pereira, and Ana Beatriz Hernández-lara. 2014. "The Morocco Brand from the Moroccan Emigrants' Perspective." Place Branding and Public Diplomacy 10(1): 55-69.

Gaming Inspection and Coordination Bureau of Macao SAR. 2019. "Monthly 
Gross Revenue from Games of Fortune."

Gilboa, Eytan. 2008. "Searching for a Theory of Public Diplomacy." Annals of the American Academy of Political and Social Science 616(1): 55-77.

Government of Macao Special Administrative Region Statistics and Census Service. 2019a. "Demographic Statistics, 2nd Quarter 2019." Accessed December 14, 2019, http://www.dsec.gov.mo/e/demo.aspx.

Government of Macao Special Administrative Region Statistics and Census Service. 2019b. "Gross Domestic Product, 2018." Accessed December 14, 2019, https://www.dsec.gov.mo/Statistic.aspx?lang=en-US\&NodeGuid=b35 edb8a-ed5c-4fab-b741-c91b75add059.

Gregory, Bruce. 2008. "Public Diplomacy: Sunrise of an Academic Field." Annals of the American Academy of Political and Social Science 616(1): 274-290. Grunig, James E. 1993. "Image and Substance: From Symbolic to Behavioral Relationships." Public Relations Review 19(2): 121-139.

Grunig, James E. and Chun-ju Flora Hung-Baesecke. 2015. "The Effect of Relatoinships on Reputation and Reputation on Relationships: A Cognitive, Behavioral Study." In Public Relations as Relationship Management: A Relational Approach to the Study and Practice of Public Relations edited by E.j. Ki, Jeong-Nam Kim and John. A. Ledingham, 63-113. New York, NY: Routledge.

Hayden, Craig. 2017. "Scope, Mechanism, and Outcome: Arguing Soft Power in the Context of Public Diplomacy." Journal of International Relations and Development 20(2): 331-357.

Ingenhoff, Diana and Jérôme Chariatte. "Solving the Public Diplomacy Puzzle a Multimethod-Design Study on What Constitutes a Country Image." Paper presented at the $69^{\text {th }}$ Annual Conference of the International Communication Association, Washington D.C., 28 May 2019.

Ingenhoff, Diana, Candace White, Alexander Buhmann, and Spiro Kiousis. 2019. "Analyzing Value Drivers and Effects of 4d Country Images on Stakeholders' Behavior across Three Different Cultures." In Bridging Disciplinary Perspectives of Country Image Reputation, Brand, and Identity edited by Diana Ingenhoff, Tianduo Zhang, Alexander Buhmann, Candace White and Spiro Kiousis, 259-288. New York: Routledge.

Ittefaq, Muhammad. 2019. "Digital Diplomacy Via Social Networks: A CrossNational Analysis of Governmental Usage of Facebook and Twitter for Digital Engagement." Journal of Contemporary Easterm Asia 18(1): 49-69.

Jiang, Y. 2016. "Social Media and E- Diplomacy: Scanning Embassies on Weibo." In The Routledge Handbook of Soft Power edited by N. Chitty, L. Ji, G. D. Rawnsley and C. Hayden. London: Routledge.

Khatib, Lina, William Dutton, and Michael Thelwall. 2012. "Public Diplomacy 
2.0: A Case Study of the Us Digital Outreach Team." The Middle East Journal 66(3): 453-472.

Kim, Jeong-Nam and J. E. Grunig. 2011. "Problem Solving and Communicative Action: A Situational Theory of Problem Solving." Journal of Communication 61(1): 120-149.

Lei, Ya-Wen. 2019. The Contentious Public Sphere: Law, Media, and Authoritarian Rule in China. Princeton, NJ: Princeton University Press.

Leong, S. 2009. "Franchise Nations: The Future of the Nation?". Continuum 23(6): 855-870.

Levitt, Peggy. 2001. "Transnational Migration: Taking Stock and Future Directions." Global Networks 1(3): 195-216.

Liu, M., J. L. Brock, G. Shi, R. Chu, and T. Tseng. 2013. "Perceived Benefits, Perceived Risk, and Trust." Asia Pacific Journal of Marketing and Logistics 25(2): 225-248.

Melissen, J. 2005. The New Public Diplomacy: Soft Power in International Relations. New York, NY: Palgrave MacMillan.

Munar, Ana María and Jens Kr Steen Jacobsen. 2014. "Motivations for Sharing Tourism Experiences through Social Media." Tourism Management 43: 46-54.

Navarrete, Celene and Esperanza Huerta. 2006. "Building Virtual Bridges to Home: The Use of the Internet by Transnational Communities of Immigrants." International Journal of Communications, Law and Policy 11: 1-20.

Ni, L. and J.-N. Kim. 2009. "Classifying Publics: Communication Behaviors and Problem-Solving Characteristics in Controversial Issues." International Journal of Strategic Communication 3: 1-25.

Pahlavi, Pierre Cyril. 2007. "Evaluating Public Diplomacy Programmes." The Hague Journal of Diplomacy 2(3): 255-281.

Pamment, James. 2014. "Articulating Influence: Toward a Research Agenda for Interpreting the Evaluation of Soft Power, Public Diplomacy and Nation Brands." Public Relations Review 40(1): 50-59.

Pamment, James. 2013. New Public Diplomacy in the 21st Century: A Comparative Study of Policy and Practice. New York: Routledge.

Pamment, James. 2018. "Public Diplomacy." In The Encyclopedia of Diplomacy edited by G. Martel: Wiley.

Payne, J. Gregory. 2009a. "Reflections on Public Diplomacy: People-to-People Communication." American Behavioral Scientist 53(4): 579-606.

Payne, J. Gregory. 2009b. "Trends in Global Public Relations and Grassroots Diplomacy." American Behavioral Scientist 53(4): 487-492.

Payne, J. Gregory, Efe Sevin, and Sara Bruya. 2011. "Grassroots 2.0: Public Diplomacy in the Digital Age." Comunicação Pública 6(10): 45-70.

Rehmet, Jonas and Keith Dinnie. 2013. "Citizen Brand Ambassadors: Motivations 
and Perceived Effects." Journal of Destination Marketing \& Management 2(1): 31-38.

Seib, Philip. 2011. Public Diplomacy, New Media, and Counterterrorism. Cpd Perspective on Public Diplomacy, Paper 2. Los Angeles: Figueroa Press.

Sevin, Efe. 2017a. "A Multilayered Approach to Public Diplomacy Evaluation: Pathways of Connection." Politics \& Policy 45(5): 879-901.

Sevin, Efe. 2017b. Public Diplomacy and the Implementation of Foreign Policy in the U.S., Sweden and Turkey. Cham, Switzerland: Palgrave Macmillan.

Sevin, Efe and Diana Ingenhoff. 2018. "Public Diplomacy on Social Media: Analyzing Networks and Content." International Journal of Communication 12: 3663-3685.

Sheng, Mingjie and Chaolin Gu. 2018. "Economic Growth and Development in Macau (1999-2016): The Role of the Booming Gaming Industry." Cities 75: 72-80.

Singh, J. P. 2015. "The Power of Diplomacy: New Meanings, and the Methods for Understanding Digital Diplomacy." In Digital Diplomacy: Theory and Practice edited by C. Bjola and M. Holmes, 181-198.

Sommerfeldt, Erich J. and Alexander Buhmann. 2019. "The Status Quo of Evaluation in Public Diplomacy: Insights from the Us State Department." Journal of Communication Management.

Sonenshine, T. 2012. "Measuring the Public Diplomacy of the Future." Accessed December 14, 2019, https://2009-2017.state.gov/r/remarks/2012/201408.htm.

Song, L. and Q. Bian. 2015. "The Eu through the Eyes of Chinese Social Media: A Case Study of the Official Micro-Blog of Chinese Foreign Ministry." International Communication Gazette 78(1-2): 64-82.

Sotiriu, S. 2015. "Digital Diplomacy: Between Promises and Reality." In Digital Diplomacy: Theory and Practice edited by C. Bjola and M. Holmes, 3351. New York: Routledge.

Spry, D. 2018. "Facebook Diplomacy: A Data-Driven, User-Focused Approach to Facebook Use by Diplomatic Missions." Media International Australia 168(1): 62-80.

Storie, Leysan Khakimova. 2015. "Lost Publics in Public Diplomacy: Antecedents for Online Relationship Management." Public Relations Review 41(2): 315-317.

Storie, Leysan Khakimova. 2018. "Relationship Cultivation in Public Diplomacy: A Qualitative Study of Relational Antecedents and Cultivation Strategies." Journal of Public Relations Research 29(6): 1-16.

Tam, Lisa and Jeong-Nam Kim. 2019. "Who Are Publics in Public Diplomacy? Proposing a Taxonomy of Foreign Publics as an Intersection between Symbolic Environment and Behavioral Experiences." Place Branding and Public Diplomacy 15(1): 28-37. 
Vibber, Kelly. 2014."Advocates or Adversaries? An Exploration of Communicative Actions of within-Border Foreign Publics and Their Affect on the Host Country's Soft Power." (Purdue University).

Vibber, Kelly and J.-N. Kim. 2015. "Diplomacy in the Globalized World: Focusing Internally to Build Relationships Externally." In International Public Relations and Public Diplomacy: Communication and Engagement edited by G. J. Golan, S.-U. Yang and D. F. Kinsey, 131-146. New York, NY: Peter Lang Publishing.

Wang, J. 2006. "Managing National Reputation and International Relations in the Global Era: Public Diplomacy Revisited." Public Relations Review 32(2): 91-96.

Yang, A. and M. Taylor. 2014. "Public Diplomacy in a Networked Society: The Chinese Government-Ngo Coalition Network on Acquired Immune Deficiency Syndrome Prevention." International Communication Gazette 76(7): 575-593.

Yin, R. K. 2013. "Validity and Generalization in Future Case Study Evaluations." Evaluation 19(3): 321-332.

Yun, Seong-Hun. 2014. "Do International Students' Direct Experiences with the Host Country Lead to Strong Attitude-Behavior Relations? Advancing Public Diplomacy Research and Beyond." International Journal of Communication 8: 787-809.

Yun, Seong-Hun. 2015. "Does Student Exchange Bring Symmetrical Benefits to Both Countries? An Exploration Case for China and Korea." International Journal of Communication 9: 710-731.

Yun, Seong-Hun. 2012. "Relational Public Diplomacy: The Perspective of Sociological Globalism." International Journal of Communication 6: 2199-2219.

Yun, Seong-Hun and Jeong-Nam Kim. 2008. "Soft Power: From Ethnic Attraction to National Attraction in Sociological Globalism." International Journal of Intercultural Relations 32(6): 565-577.

Yun, Seong-Hun and Elizabeth L. Toth. 2009. "Future Sociological Public Diplomacy and the Role of Public Relations: Evolution of Public Diplomacy." American Behavioral Scientist 53(4): 493-503.

Yun, Seong-Hun and Kelly Vibber. 2012. "The Strategic Values and Communicative Actions of Chinese Students for Sociological Korean Public Diplomacy." International Journal of Strategic Communication 6(1): 77-92.

Zaharna, Rhonda S., Amelia Arsenault, and Ali Fisher. 2014. Relational, Networked and Collaborative Approaches to Public Diplomacy: The Connective Mindshift. New York: Routledge. 